\title{
Indoor air quality in health clubs: Impact of occupancy and type of performed activities on exposure levels
}

Klara Slezakova $^{a, b, 1}$, Cátia Peixoto ${ }^{a, 1}$, Maria do Carmo Pereira ${ }^{b, *}$, Simone Morais $^{a, *}$

a REQUIMTE-LAQV, Instituto Superior de Engenharia do Porto, Instituto Politécnico do Porto, R. Dr. António Bernardino de Almeida 431, 4200-072 Porto, Portugal

b LEPABE, Departamento de Engenharia Química, Faculdade de Engenharia, Universidade do Porto, R. Dr. Roberto Frias, 4200-465 Porto, Portugal

\section{A B S T R A C T}

Associations between indoor air quality (IAQ) and health in sport practise environments are not well understood due to limited knowledge of magnitude of inhaled pollutants. Thus, this study assessed IAQ in four health clubs ( $\mathrm{HC} 1-\mathrm{HC} 4)$ and estimated inhaled doses during different types of activities. Gaseous (TVOCs, $\left.\mathrm{CO}, \mathrm{O}_{3}, \mathrm{CO}_{2}\right)$ and particulate pollutants $\left(\mathrm{PM}_{1}, \mathrm{PM}_{4}\right)$ were continuously collected during 40 days. IAQ was influenced both by human occupancy and the intensity of the performed exercises. Levels of all pollutants were higher when clubs were occupied $(p<0.05)$ than for vacant periods, with higher medians in main workout areas rather than in spaces/studios for group activities. In all spaces, TVOCs highly exceeded legislative limit $\left(600 \mu \mathrm{g} / \mathrm{m}^{3}\right)$, even when unoccupied, indicating possible risks for the respective occupants. $\mathrm{CO}_{2}$ levels were well correlated with relative humidity $\left(r_{s}\right.$ 0.534-0.625) and occupancy due to human exhalation and perspiration during exercising. Clubs with natural ventilations exhibited twice higher $\mathrm{PM}$, with $\mathrm{PM}_{1}$ accounting for $93-96 \%$ of $\mathrm{PM}_{4}$; both $\mathrm{PM}$ were highly correlated $\left(r_{s} 0.936-0.995\right)$ and originated from the same sources. Finally, cardio classes resulted in higher inhalation doses than other types of exercising (1.7-2.6). 
Environmental pollution is a major cause of disease, disability, and premature death worldwide. Annually, 9 million of deaths (i.e. $16 \%$ of all deaths worldwide) are caused by environmental pollution alone [1], which is approximately three times more that combined mortalities from severe diseases such as tuberculosis, AIDS and malaria [2]. Out of these, 6.5 million of deaths are annually caused by air pollution alone [2]. Apart from respiratory and cardiovascular diseases, air pollution has been associated with various adverse health effects (cancers of different organs, impaired neuro- and cognition development, diabetes - type 2) [3]. Air pollution might be also a risk factor for obesity $[3,4]$, which is relevant for nowadays sedentary society [5,6]; in western European countries more than half of current adult population ( $\geq 20$ years) is overweight or even obese [7]. Due to the high exposure risks even at low concentrations of pollutants [8], air pollution effects are especially relevant in indoor environments, where people spend $90 \%$ of their daily time. The prolonged duration and lesser degree of dilution and/or pollutant dispersion indoors may eventually lead to indoor exposures of several magnitudes larger than those from ambient air [[9], [10], [11]]. Furthermore, humans and their activities are significant factor indoors [12]. Several studies have reported or even quantified human contribution to indoor concentration of various pollutants $[9,12]$. Thus, it is particularly relevant to assess levels of indoor air quality (IAQ) in places, such as fitness centres or gyms, where a significant part of pollution is assumingly caused by the occupants $[9,13]$, yet simultaneously, increased ventilation rates (due to physical exertion) expose body to much great amount of pollution; inadequate IAQ in these places can easily counteract the well-being benefits of physical exercise $[14,15]$.

During last years many studies have produced information regarding IAQ, with specific attention to indoor microenvironments (pre- and primary/elementary schools, homes, offices, hospitals and etc. [[16], [17], [18], [19], [20], [21], [22], [23], [24], [25], [26], [27], [28]]), as well as some specific occupational settings [[29], [30], [31]]. However, indoor sport environments have been studied considerably less. The main scientific focus was on particulate matter (namely PM10, PM2.5, PM1), with data coming either from educational settings (elementary/primary schools gymnasiums, university sport facilities; [9,[12], [13],[32], [33], [34], [35], [36], [37], [38], [39], [40]]) or from sport facilities (gymnastic and sport halls; [[41], [42], [43], [44], [45]]); health or fitness clubs have been addressed considerably less [15,[46], [47], [48], [49]]. World Health Organization (WHO) recommends 150 (at least) -300 min (for additional benefits) of moderate-intensity physical activity per week [50], which translates approximately to $1 \mathrm{~h} /$ day on 5 days/week. Time and frequency spent in these places indicate the need of further 
assessment of IAQ and its impacts on human health in order to develop strategies to control and reduce the respective risks.

This study evaluated IAQ in indoor fitness clubs and estimated potential inhalation doses. Concentrations of gaseous (total volatile organic compounds - TVOCs, ozone - O3, and carbon dioxide - CO2) and particulate (PM4 and PM1) pollutants, and comfort parameters in indoor air of four health clubs were evaluated. Secondly, inhalation doses for the respective occupants (exercising subjects and fitness instructors) were assessed considering three different age categories of males and females, under various types of physical activity (individual training and group classes).

\section{Materials and methods}

2.1. Sampling

Indoor air quality sampling was done in four health clubs (HC1-HC4) in spring 2014 (May-June) during 40 consecutive days (weekdays, weekends). All clubs were situated in urban zones of Oporto Metropolitan Area; road traffic and local industry were the main emission sources of the respective sites [51,52]. HC1-HC2 were smaller and simpler local gyms. HC3-HC4 were large, sophisticated health clubs (internationally recognized) that accommodated $\sim 400$ up 1000 clients/day. Detailed descriptions of all clubs and their facilities are summarized in Table $1 \mathrm{~S}$ of the Supplementary material.

Samplers were mounted on supports $(\sim 1.4 \pm 0.2 \mathrm{~m})$, and at least $1.5 \mathrm{~m}$ from walls to minimize the influence on pollutant dispersion [53,54]; location of samplers was chosen in order to avoid any direct influence (opened windows/doors, mechanical ventilation systems, cleaning product emissions, and etc.). Gaseous pollutants (TVOCs, $\mathrm{CO}, \mathrm{O} 3$, and CO2) were sampled by a multi-gas sensor probe (model TG 502; GrayWolf Sensing Solutions, Shelton, USA; accuracy $\pm 2 \%$ reading for $\mathrm{CO}$ and TVOCs; $\pm 3 \%$ reading for $\mathrm{CO} 2$ and O3). PM4 and PM1 were monitored by TSI DustTrak DRX photometer (model 8533; TSI Inc., MN, USA; flow rate of $3.0 \mathrm{~L} / \mathrm{min}$ ). Temperature $(T)$ and relative humidity $(\mathrm{RH})$ were recorded by Testo mini data-logger (model $174 \mathrm{H}$; Testo AG, Lenzkirch, Germany) (Fig. 2S). All equipment was calibrated (at the manufacturers) prior to the sampling campaign. Additionally, readings of multi-gas sensor probe were weekly checked using calibration standards (difference $<5 \%$ ) and adjusted according to the manufacturer's instructions. In order to minimize the occurrences of sudden artefact jumps in PM concentrations [55], photometer was daily zeroed (using external zeroing module). 
Air quality sampling was done continuously (with 1 min logging interval); each day approximately 1400 values were recorded. In each club, sampling was consecutively conducted in various places (Fig. 1): (i) main workout areas (MWA; a joint space with free weights, bodybuilding machines and cardiovascular training-related equipment), (ii) rooms/studios for group classes (SGA); technical areas (receptions, storage rooms, locker rooms, or spa centers for HC3 and HC4; Table 1S) were not considered.

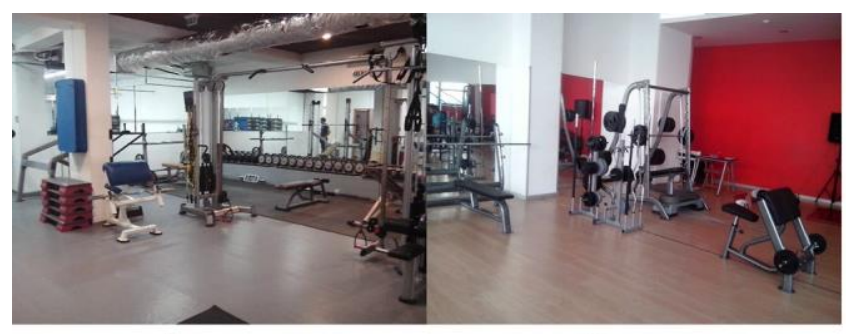

a)

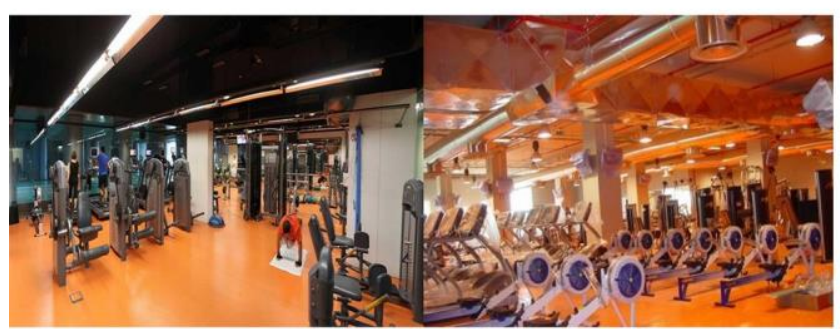

c) b)

d)

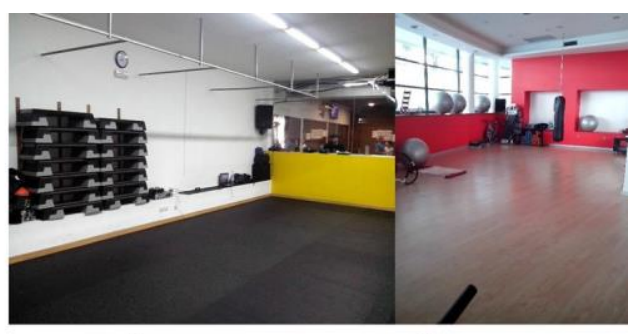

e)

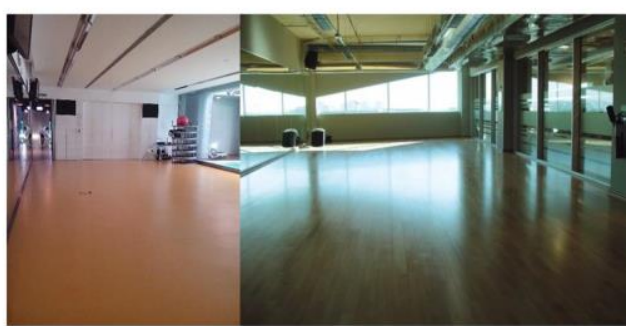

g) h)

Fig. 1. Visualizations of indoor spaces at health clubs $(\mathrm{HC} 1-\mathrm{HC} 4)$ : (a-d) main workout areas; (e-h) rooms/studios for group classes.

All pertinent information in regards to indoors and outdoors of the clubs (cleaning schedules, club occupancy, ventilations, ambient emission sources and etc.) was collected by a team member who was continuously present on site; staff of each club provided further information regarding any untypical occurrence/situations. Information regarding ambient air quality during the respective period is summarized in Table $2 \mathrm{~S}$.

\subsection{Inhalation dose calculations}

Inhalation doses calculation was determined according to the previous methodology [37,56,57], but for readers convenience details are summarized in SM (Text 1S). Considered scenarios included: (i) workout training (60 min; in MW), and classes (50 min; SGA) either "mind or body" or with "dynamic cardiovascular exercising". Gender/weight specific parameters were adapted from USEPA [58] considering four age categories and also occupational exposure (instructors; Table 3S). 
Statistical analysis was performed by Microsoft Excel 2013 (Microsoft Corporation), SPSS (IBM SPSS Statistics 20), and Statistica software (v. 7, StatSoft Inc., USA). As Shapiro - Wilk's test did not confirm normal distributions of the obtained data, nonparametric Mann - Whitney $U$ test was used to compare the respective medians (threshold of statistical significance set at $p<0.05$ ).

\section{Results and discussion \\ 3.1. Gaseous pollutants}

Over the sampling campaign, the levels of TVOCs (Fig. 2a) highly varied. Concentration ranges were especially large in $\mathrm{HC} 1$ and $\mathrm{HC} 2$, with values, respectively, between $14 \mu \mathrm{g} / \mathrm{m} 3-21.8 \mathrm{mg} / \mathrm{m} 3$ (median of $1.4 \mathrm{mg} / \mathrm{m} 3$ ), and $2 \mu \mathrm{g} / \mathrm{m} 3-20.4 \mathrm{mg} / \mathrm{m} 3$ (median of $1.1 \mathrm{mg} / \mathrm{m} 3$ ). In HC3 and HC4, i.e. clubs equipped with controlled ventilations (Table 1S), obtained concentration ranges were approximately 23 times lower: $73 \mu \mathrm{g} / \mathrm{m} 3-12.4 \mathrm{mg} / \mathrm{m} 3$ at $\mathrm{HC} 3$, and $3 \mu \mathrm{g} / \mathrm{m} 3-8.0 \mathrm{mg} / \mathrm{m} 3$ at HC4. Considering different spaces of each club (MWA vs. SGA), the highest TVOCs medians were observed in HC3 (MWA: 2.6$5.0 \mathrm{mg} / \mathrm{m} 3$, SGA: 2.3-2.8 mg/m3) whereas the lowest were in HC4 (236-386 $\mu \mathrm{g} / \mathrm{m} 3$ and 600-1090 $\mu \mathrm{g} / \mathrm{m} 3$ in MWA and SGA, respectively). Overall, TVOCs levels (both medians and ranges) were higher in MWA rather than SGA. These findings were understandable considering larger use and scope of this type of indoor space (in terms of number of exercising subjects, conducted activities, respective emissions, etc.). Considering harmful health effects of these compounds, WHO provides guidelines for some individual VOCs in indoor air (such as benzene, trichloro- and tetrachloroethylene; [59]), whereas the Portuguese legislation on IAQ in public buildings [60] defines a protection limit expressed as total VOCs $(600 \mu \mathrm{g} / \mathrm{m3}$; $8-\mathrm{h}$; Table $4 \mathrm{~S})$. This limit value was highly exceeded (3-5 times) in $88 \%$ of the analysed indoor spaces (both MWA and SGA) even when considering, more restrictively, median concentrations (Figs. 2a, 1Sa). It is alarming that concentrations exceeded (up to 8 times) the limit, even during off-hours (i.e. when unoccupied). From the limited available information, it should be noted that in general, the TVOCs obtained in the four characterized HC were higher than in other published works $[32,86,103,104]$. Alves et al. [32] reported TVOCs in a range of 35-2318 ppb (means of 53-82 ppb) in university sport facility (Léon, Spain), but that setup (a court, partly opened construction) was very different from a typical health club setting; opening doors and windows results in lower TVOCS [103]. From a national perspective, TVOCs in the four HC were still higher than in other indoor environments, including primary schools in Porto (range: 2-820 $\mu \mathrm{g} / \mathrm{m} 3$ [86]) or in Lisbon (range 100-500 $\mu \mathrm{g} / \mathrm{m} 3$ [104]), and in home bedrooms (range: 0.20-1.47 $\mu \mathrm{g} / \mathrm{m3}$ [103]). As VOCs are released from various personal-care products (perfumes, hair sprays, hand disinfectants; [61]), increased VOCs (monoterpenes) have been reported in confined spaces due to occupant's activity [62]. Furthermore, VOCs are directly emitted from humans themselves (exhaled breath, perspiration; [[63], [64], [65]]), but secondary oxidation reactions between ozone and human skin lipids (with squalene being the major precursor) can be a relevant VOCs source $[66,67]$. In agreement, in HC1HC2 TVOCs concentrations were higher $(p<0.05)$ when occupied (Figs. 3a, 3S). However, in HC3- 
HC4, this trend was opposite, with increased (20-90\%) TVOCs during unoccupied periods. These elevated concentrations most likely resulted from pollutants accumulation (Fig. 3a), as ventilation systems were off during night. In addition, in HC3 (exhibited the highest levels both during occupied and off-hours), rooms layout (central swimming pool area surrounded by spaces to exercise; separated only by glass panel; Fig. 1c, g; Table 1S) led to direct connection between the spaces. Use of cleaning and sanitation products, as well as maintenance processes to disinfect pool water/the respective area can generate VOCs [68] that consequently infiltrated to exercise spaces. Thirdly, the main cleanings were conducted during off-hours, which might also elevate the respective TVOCs (when unoccupied), as previously reported [32]. Finally, in regards to intra-space comparison, HC4 was the only club where TVOCs in MWA were $\sim 3$ lower than at SGA (Fig. 2a). The respective MWA room volume was significantly ( $\sim 11$ times) larger (vs. HC1-HC3: MWA room volume $\sim 2$ times larger than SGA; Table 1S), which might resulted in emissions dilution in the respective room.

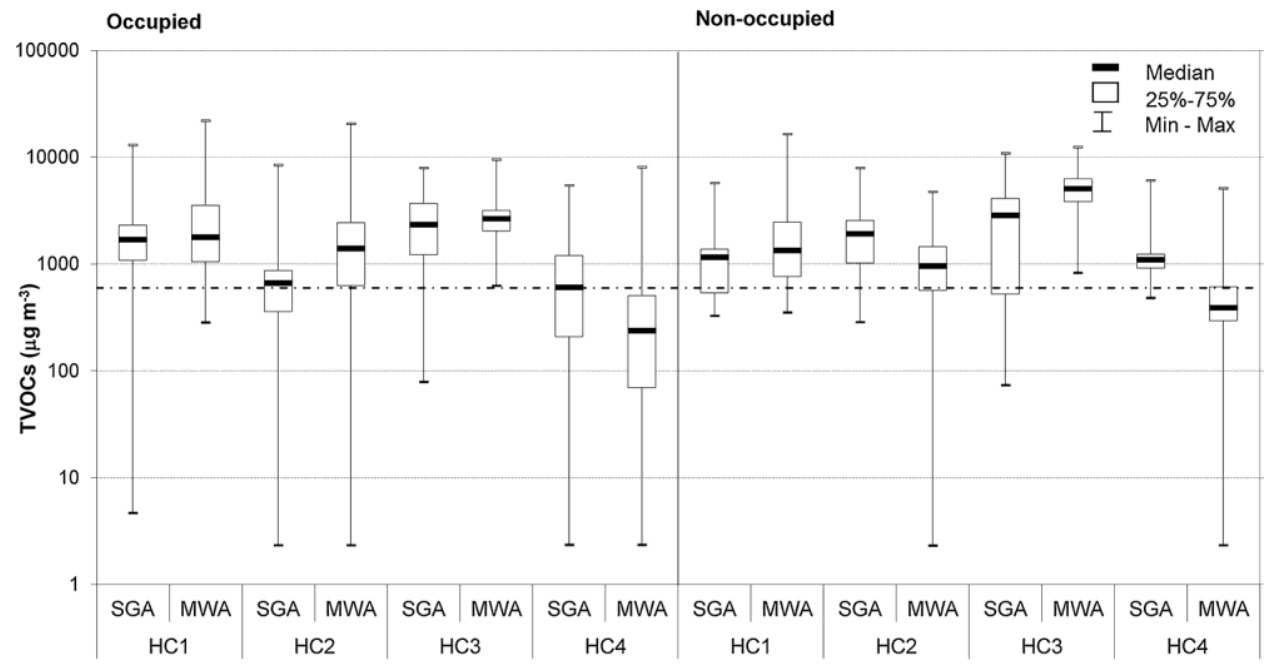

Fig. 2. Levels of gaseous pollutants ( $\square$ median; $\square 25^{-1}-75 \%$, and range) at health clubs (HC1-HC4) during occupied and non-occupied periods: (a) TVOCs; (b) CO2; and (c) O3. Horizontal dashed lines represent limit values set by Portuguese legislation (Decret 
a)
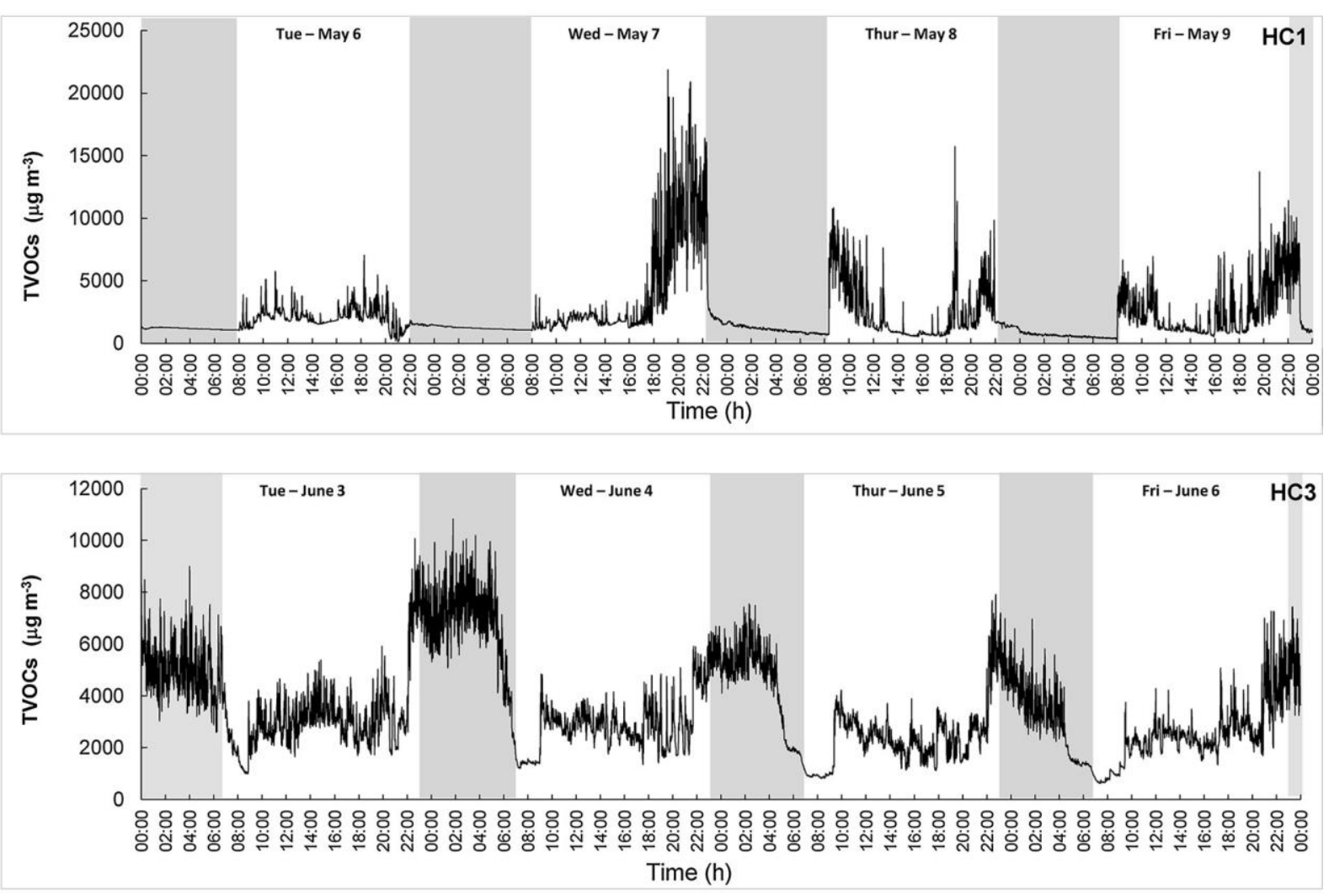

b)
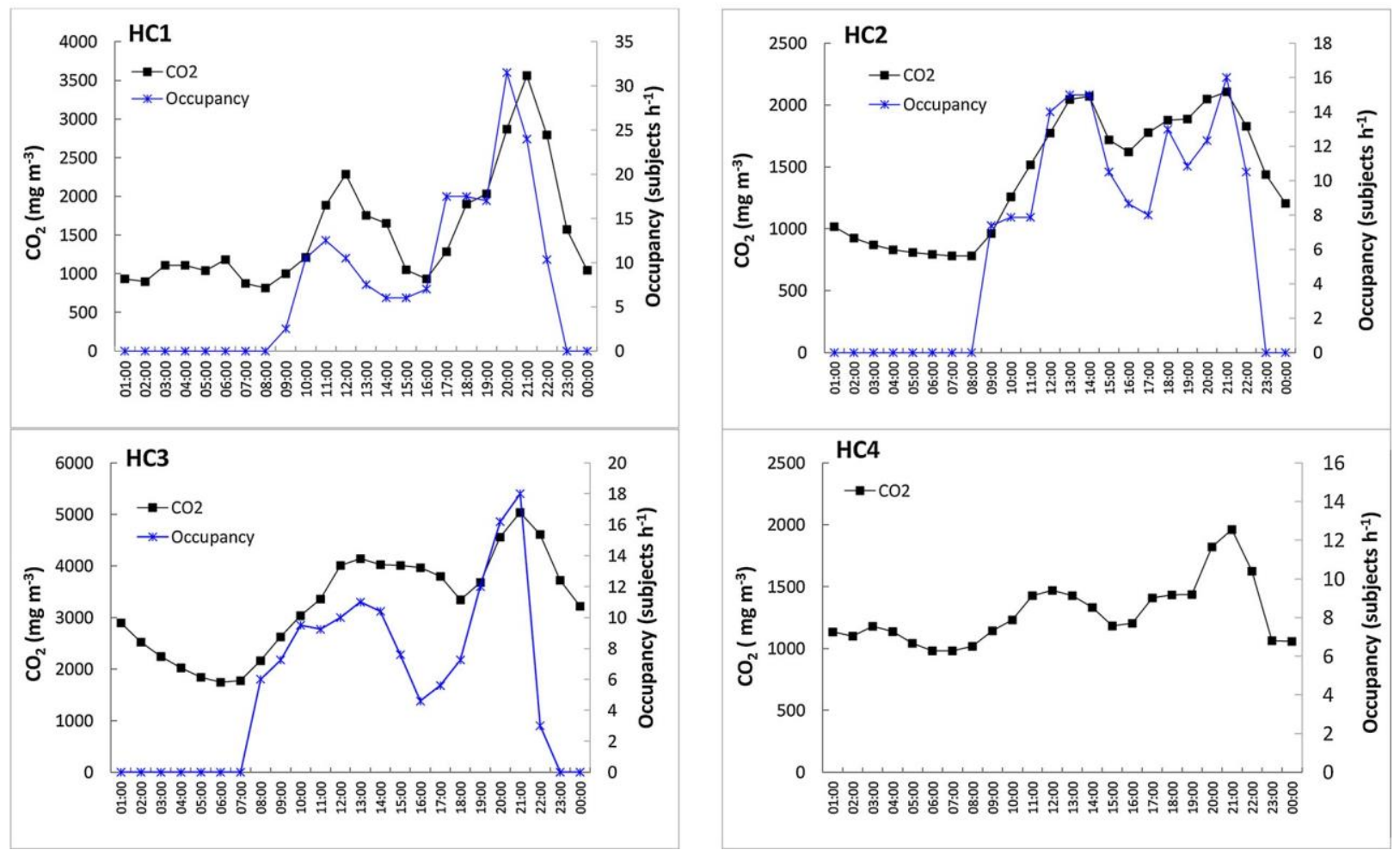

Fig. 3. Temporal variations of gaseous pollutants: (a) examples of continuous evolution (4 weekdays) of levels of total volatile organic compounds levels (main workout areas) of HC1 and HC3 (grey scale indicates unoccupied periods; (b) mean daily variations of $\mathrm{CO} 2$ at four clubs $(\mathrm{HC} 1-\mathrm{HC} 4)$ and the respective occupancies (note: occupancy profile of HC4 is not presented due to the proprietor restrictions. 
CO2 median concentration across $\mathrm{HC}$ was $1558 \mathrm{mg} / \mathrm{m} 3$, with values ranging between 733$8122 \mathrm{mg} / \mathrm{m} 3$ at $\mathrm{HC} 1,697-5299 \mathrm{mg} / \mathrm{m} 3$ at HC2, 1046-7649 mg/m3 at HC3, and 252-49007 mg/m3 at HC4. In all HC, CO2 were significantly higher (up to 2 times) when occupied; these differences were especially obvious in clubs with natural ventilations (60-120\% in HC1-HC2 vs. 20-80\% in HC3-HC4). Temporal CO2 maxima exceeded standard of $2250 \mathrm{mg} / \mathrm{m} 3$ set in Portuguese standard in all analysed spaces (Fig. 2b) as well as the stricter recommendation of the American Society of Heating, Refrigerating, and Air-Conditioning Engineers (ASHRAE; $1800 \mathrm{mg} / \mathrm{m3}$ ) [69]. Furthermore, when occupied, median concentrations were higher than the limit in $75 \%$ of all analysed spaces, indicating insufficient ventilation. Similarly to TVOCs, higher levels were observed in MWA (higher number of subjects), presenting the highest median concentrations $(4537 \mathrm{mg} / \mathrm{m3}$; $\sim 2$ higher than limit value) at MWA of HC3. In this club, medians CO2 (MWA) exceeded limit even when unoccupied, indicating overall inadequate air quality. Whereas $\mathrm{CO} 2$ is not a hazardous pollutant at the levels detected in $\mathrm{HC}$ [69], exposure to moderate concentrations of $\mathrm{CO} 2$ can cause changes in human performances and influence decision-making [70]. CO2 daily profiles (Fig. 3b) exhibited two maxima: typically around midday (approx. at 12-13 h) and at early evening hours (approx. at 20-21 h). The lowest CO2 levels were observed during early mornings and early afternoons (approx. at 8-9 and 15-16 h). Indoors, respiration of the respective occupants is the primary $\mathrm{CO} 2$ source, and $\mathrm{CO} 2$ profiles well corresponded with occupancies of the clubs (Fig. 3b). The mean concentrations of $\mathrm{CO} 2$ (that were estimated in relation I to room occupancy; Table 5S) ranged between 143 and $284 \mathrm{mg} / \mathrm{m} 3$ per occupant in SGA and 284-735 mg/m3 per occupant in MWA. While high variations of the obtained values were observed, it is possible to highlight that in all HC, MWA always exhibited higher (2-4 times higher) levels than in SGA, mostly likely due to higher occupancy of the respective spaces. Taking into consideration the dimensions and sizes of the spaces, CO2 factors ranged 0.6$1.4 \mathrm{mg}$ /occupant in SGA and 0.5-1.5 mg/occupant in MWA; the intra-space comparison being similar in a given club (Table 5S). However, it is important to emphasize that the indoor $\mathrm{CO} 2$ concentrations are also influenced by metabolic activity of occupants [48] and physical parameters of the room (air exchange rates), which were not assessed in this work.

Overall, levels and distributions of ozone (Figs. 2c; 1Sc, Supplementary material) varied among HC $(p<0.05)$, with the following ranges: $20-118 \mu \mathrm{g} / \mathrm{m} 3$ at FC1, 20-1660 $\mu \mathrm{g} / \mathrm{m} 3$ at FC2, 20-1100 $\mu \mathrm{g} / \mathrm{m} 3$ at FC3, and 20-2490 $\mu \mathrm{g} / \mathrm{m3}$ at FC4. Over that period, the daily concentrations of ozone (maximum 8-h mean) in ambient air ranged between 39.8-119 $\mathrm{gg} / \mathrm{m} 3$ (Table 2S), being below the indicated limit of $120 \mu \mathrm{g} / \mathrm{m} 3$ [105]. These levels need to be implicated carefully, once the concurrent measurements of ozone in outdoor air were not conducted directly in the HC vicinities; data were retrieved from the national monitoring network, for each $\mathrm{HC}$ considering a station that was situated the closest to it and with characteristics similar to those of health club site. Similarly to TVOCs and CO2, the highest medians were observed in spaces of HC3 (occupied periods SGA: $138 \mu \mathrm{g} / \mathrm{m3}$; MWA: $158 \mu \mathrm{g} / \mathrm{m} 3$ ). Thus HC3 spaces (both MWA and SGA) were the most polluted ones; increased levels of gaseous 
pollutants (often exceeding the guidelines even during unoccupied periods) indicate the need to improve the respective IAQ. Once again, ozone showed temporal variations and exhibited significantly higher levels $(p<0.05)$ during occupied periods. Indoor sources of ozone include equipment (photocopiers, printers, or air cleaners [71,72]), but the major source of ozone is the ambient air and the majority of ozone indoors results from infiltrations (due to ventilation) [106]. Consequently, the use of exhaust ventilation systems may produce lower concentrations of ozone indoors than would have occurred when using natural ventilation systems (considering the same air-exchange rate) [107]. In agreement, in clubs with natural ventilations $\mathrm{HC} 1-\mathrm{HC} 2$, the differences of ozone levels during occupied vs. unoccupied were approximately twice higher (65-120\%) than in clubs that were equipped with mechanical ventilation ( 20-80\%). Though there are no regulation for ozone indoors (Table 4S), its negative health impacts have been recognized, with recommendation to mitigate indoor ozone to ALARA levels (i.e. as low as reasonably achievable [73]). It is rather difficult to compare the obtained results with other studies, as information regarding indoor ozone in sport facilities is very limited (Table 6S). Some authors [48] reported fitness clubs with ozone concentrations of $0-0.17 \mathrm{mg} / \mathrm{m} 3$, being somewhat similar to this study. Nevertheless, due to different study design (45-60 min long measurements conducted when the most occupied, i.e. late afternoon/night), the attained findings need to be implicated carefully. Additional information on ozone was reported for sport halls [44], with mean levels of 8-19 $\mathrm{mg} / \mathrm{m} 3$ (depending on the event happenings). Obviously, these concentrations differed due to their dissimilar characteristics. Furthermore, both these studies also included VOCs and CO2 assessments. Information concerning these pollutants (though still limited for fitness/health clubs) consists of more data mainly from evaluations of sport halls $[42,43]$ and educatory environments (primary/elementary school gymnasiums, university centres, etc.) [9,32]. Considering specifically fitness clubs [48], the reported means (CO2: 524-4418 mg/m3; TVOCs 0-3.3 mg/m3) were in similar ranges as in presented work. In all HC, ozone was positively moderately (rs: 0.487-0.643 at HC1$\mathrm{HC} 2, \mathrm{HC} 4$ ) to highly (rs: 0.835 at HC3) correlated with TVOCs, indicating associations between these pollutants. Ozone is a reactive pollutant and its indoor chemistry (i.e. ozone-initiated reactions) can create gaseous products, which may be even more reactive and/or heath-hazardous [[74], [75], [76], [77], [78]]; insufficient air exchange rate can then increase levels of ozone-reactive VOCs [79]. These processes may be influenced by room occupancy $[77,80]$ as humans are significant sinks for ozone indoor concentrations due to skin lipids that react with ozone to produce characteristic oxidation products [67].

Finally, 59-68\% of the registered values for CO were below LODs (mainly in HC1, HC2, HC4). Thus, this pollutant was not further analysed. However, the obtained levels across four HC (median $0.181 \mathrm{mg} / \mathrm{m} 3$ at $\mathrm{HC} 1-1.26 \mathrm{mg} / \mathrm{m} 3$ at $\mathrm{HC} 3$ ) were well below guideline limit of $10 \mathrm{mg} / \mathrm{m} 3$, indicating that $\mathrm{CO}$ was not a concern in the respective environments. Nevertheless, as this pollutant is toxic to human health, its presence should be monitored. 


\subsection{Particulate matter}

Similarly to gaseous pollutants, PM levels highly varied. At HC1 and HC2, PM4 ranged, respectively, 5-368 $\mu \mathrm{g} / \mathrm{m} 3$ (median $38 \mu \mathrm{g} / \mathrm{m} 3$ ) and 6-829 $\mu \mathrm{g} / \mathrm{m} 3$ (median $21 \mu \mathrm{g} / \mathrm{m} 3$ ). The corresponding PM1were: 5-328 $\mu \mathrm{g} / \mathrm{m} 3(36 \mu \mathrm{g} / \mathrm{m} 3)$ at $\mathrm{HC} 1$ and 6-638 $\mu \mathrm{g} / \mathrm{m} 3(20 \mu \mathrm{g} / \mathrm{m} 3)$ at HC2. In the larger HC, PM varied considerably less: PM4 of 11-78 $\mu \mathrm{g} / \mathrm{m} 3$ (median $20 \mu \mathrm{g} / \mathrm{m} 3$ ) and PM1 of 11-75 $\mu \mathrm{g} / \mathrm{m} 3$ (19 $\mu \mathrm{g} / \mathrm{m} 3)$ at $\mathrm{HC} 3$; at $\mathrm{HC} 4$ the respective levels were 3-105 $\mu \mathrm{g} / \mathrm{m} 3(15 \mu \mathrm{g} / \mathrm{m} 3)$ for PM4 and 3-102 $\mu \mathrm{g} / \mathrm{m} 3$ (14 $\mu \mathrm{g} / \mathrm{m} 3$ ) for PM1 (Fig. 4S, Supplementary material). These results showed that at HC1$\mathrm{HC} 2$, the respective PM ranges were significantly higher $(p<0.05)$ although these clubs daily accommodated fewer clients (118-265 per day vs. up to 410-1000 clients/day in HC3-HC4). Apart from natural ventilation, these clubs were situated directly on a street level (ground floor; Table 1S) with windows facing busy roads (414-1338 vehicles/day; Fig. 5S). Thus, indoor PM might result from infiltrations of ambient emissions. Similarly, previous studies $[81,82]$ reported higher infiltrations of ambient particulate emissions under natural ventilation conditions (i.e. windows opening) than when using mechanical systems. During the respective period, PM levels in ambient air were on lower-end (Table 2S), ranging between $6-41 \mu \mathrm{g} / \mathrm{m} 3$ and $1-9 \mu \mathrm{g} / \mathrm{m} 3$ for PM10 and PM2.5 (24-h means), respectively. These ranges fulfilled the regulatory guidelines (24-h PM10 average $<50 \mu g / m 3$ [105]). The concentrations of fine particles seemed particularly low for urban environments, however, on European scale, Portugal exhibits relatively low PM2.5 levels [108]; the estimated average $(4 \pm 2$ $\mu \mathrm{g} / \mathrm{m} 3$ ) fulfilled EU annual limit of $25 \mu \mathrm{g} / \mathrm{m} 3$ but also the more stringent recommendation of WHO of $10 \mu \mathrm{g} / \mathrm{m} 3$ [109]. Although there is more data on PM in sport environments (compared to gaseous pollutants), the majority comes from educational sport facilities [9,12,13,[32], [33], [34], [35], [36],[38], [39], [40]]. Fitness/health clubs though have different goals than school/university gyms, and thusly represent different indoor environment (in terms of design, occupancy and conducted activities, available facilities, construction and used materials; [83]). Only few IAQ studies were conducted in fitness clubs. The main information comes from series of works [15,48,84] conducted in Lisbon (Portugal), with PM1 means in a range of 0.9-18 $\mu \mathrm{g} / \mathrm{m} 3(\mathrm{PM} 2.5: 1.5-23 \mu \mathrm{g} / \mathrm{m} 3)$. These levels were fairly similar to those in $\mathrm{HC} 3-\mathrm{HC} 4$ (i.e. with ventilation systems) considered in the present study.

In majority of places $(\mathrm{HC} 1-\mathrm{HC} 3)$, levels of both PM were lower $(\mathrm{p}<0.05)$ when clubs were vacant (Fig. 4). The difference between PM concentrations during both periods was especially distinctive at HC2 where, when occupied, PM temporarily reached levels 13-42 times higher than when closed (means: 31 and $28 \mu \mathrm{g} / \mathrm{m} 3$ for PM4 and PM1 when occupied vs. $20 \mu \mathrm{g} / \mathrm{m} 3$ and $19 \mu \mathrm{g} / \mathrm{m} 3$ for non-occupied; $\mathrm{p}<0.05)$. Thus, it is assumed that high indoor PM levels obtained in HC2 were greatly influenced by human occupancy. However, because of the high traffic density in streets surrounding HC2 (Fig. 5S), it is likely that indoor PM patterns were influenced by the infiltrations of outdoor emissions due to use (or absence, i.e. - closed windows when unoccupied) of natural ventilations. Therefore, in future studies on assessment of air exchange rate would be important to clarify these findings. Finally, apart from human activities $[13,85]$, the characteristics of the built environment (i.e. layout, used materials, type of 
ventilation, indoor sources and etc.; $[20,81,85,86])$ may strongly impact the respective indoor concentrations. The highest PM levels were observed in HC1. When occupied, PM1 medians at both spaces of $\mathrm{HC} 1$ even exceeded the PM2.5 WHO indoor air quality guideline (25 $\mu \mathrm{g} / \mathrm{m} 3$ for $24 \mathrm{~h}$; [59]) but also the Portuguese norm ( $25 \mu \mathrm{g} / \mathrm{m} 3$ over $8 \mathrm{~h}$; [60]), thus indicating possible risks. Exercising in areas with increased PM concentrations may increase adverse health effects, as deposition of particulates doubles with increased intensity of exercise [35]. Moreover, PM deposition into respiratory tract may be up to five times higher during moderate activity than at rest [9]. Maintenance works (construction and consequent cleaning) that was repeatedly carried out in SGA of $\mathrm{HC} 1$ during the offhours (i.e. late at night; Fig. 5a), probably caused the reoccurring events of elevated PM (up to 6-7 times) and resulted in overall increased PM4 and PM1 medians (25 and 30\% higher for PM4 and PM1, respectively) during unoccupied periods. HC4 was the only club where PM levels were always higher during off-hours (13 vs. $24 \mu \mathrm{g} / \mathrm{m} 3$ for both PM). These results were somewhat unexpected. However, previously increased PM when the respective places were unoccupied were reported [33,87], resulting either from secondary formations of aerosols (due to VOC emissions from cleaning products;[88]) and/or accumulation of PM indoors due to motionless air conditions that prevented mixing [87]. The intra-space comparisons also demonstrated a greater range of PM levels during occupied periods than when vacant. PM medians were statically different $(p<0.05)$ between two spaces; in agreement with gaseous pollutants, higher PM4 and PM1 medians $(p<0.05)$ were observed in MWA rather than in SGA. 


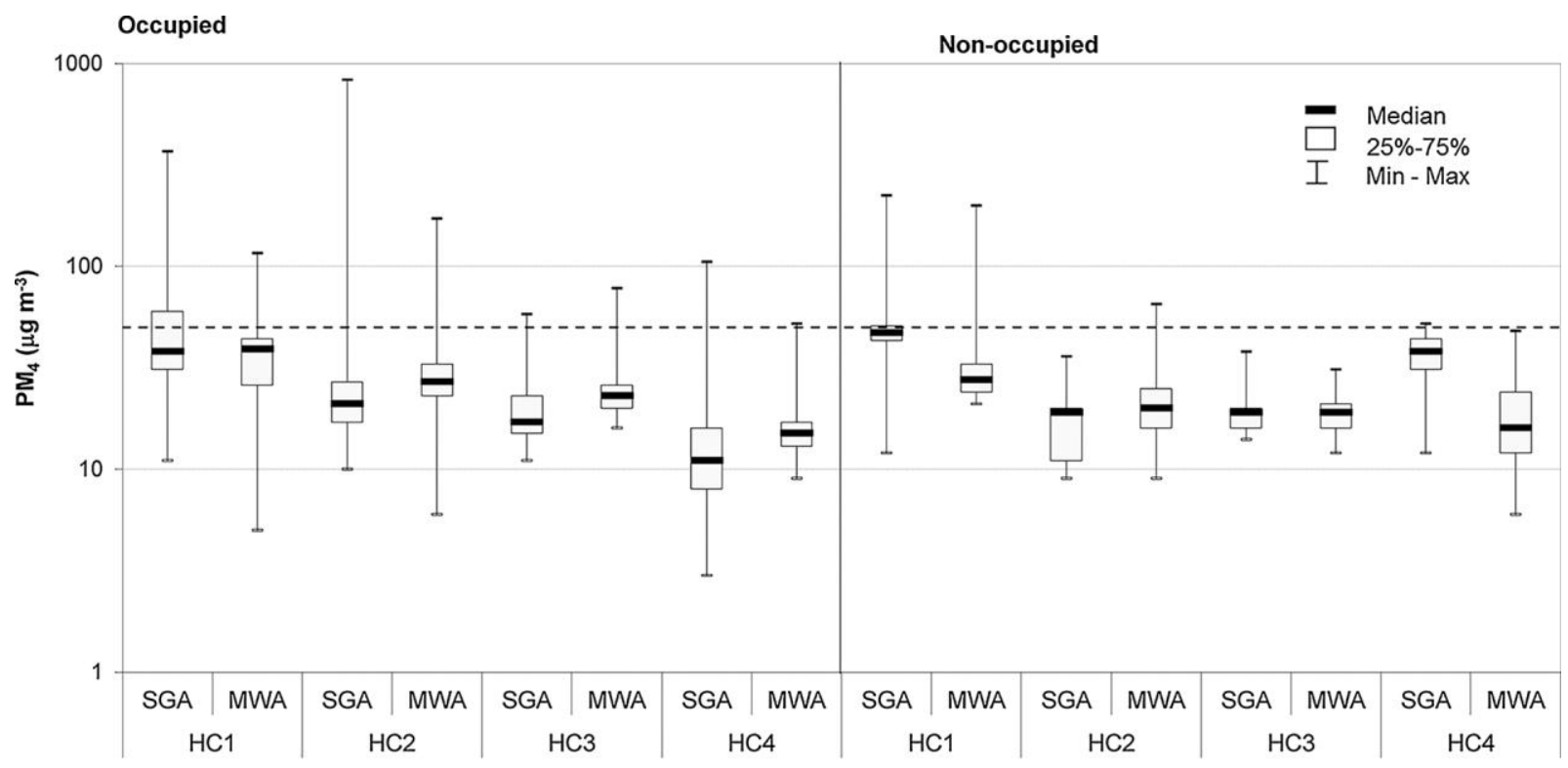

a)

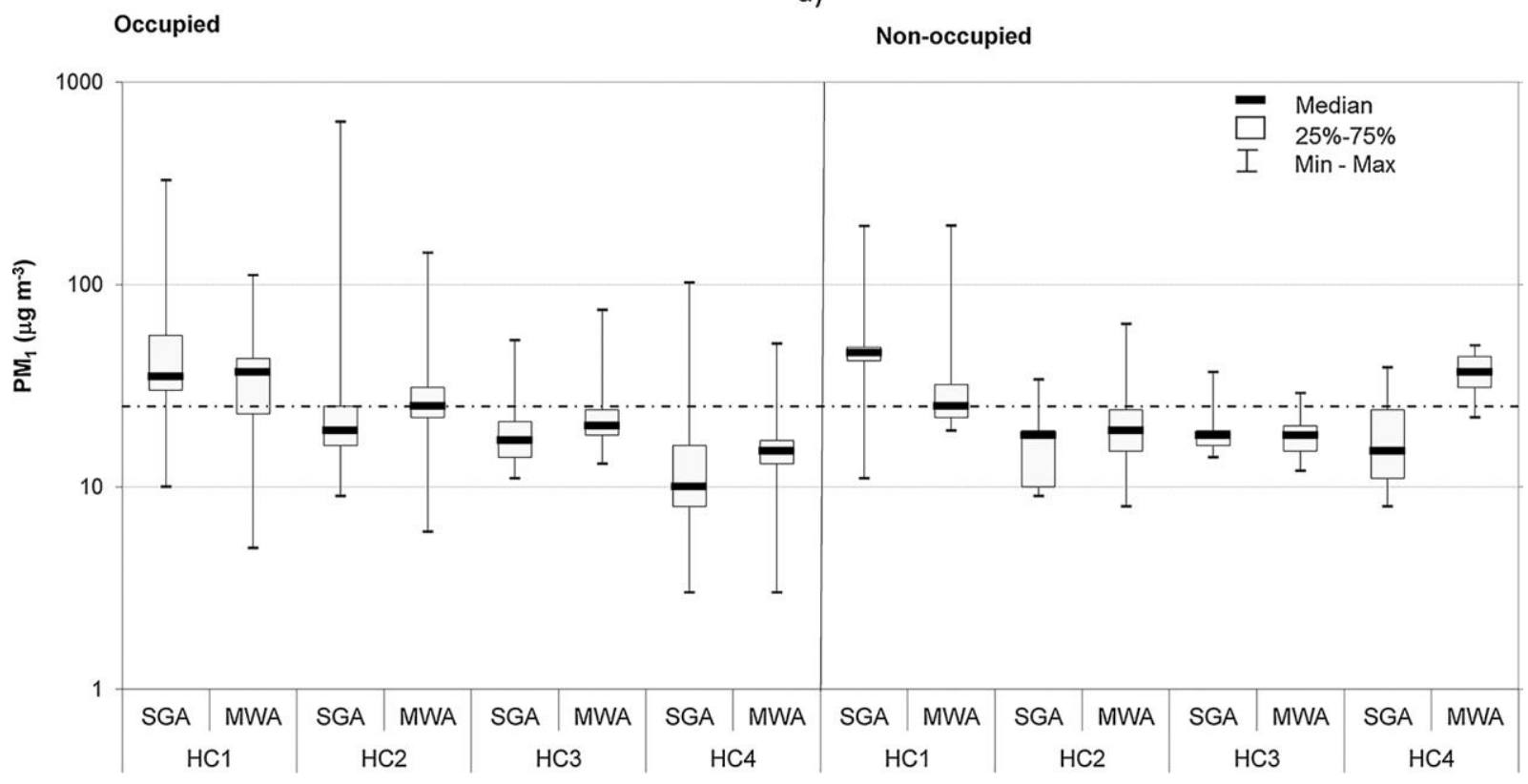

b)

Fig. 4. Levels of particulate pollution-(- median; $\square 25-75 \%$, and range) at health clubs (HC1-HC4) during occupied and non-occupied periods: (a) PM4; and (b) PM1. Horizontal dashed lines represent 8-h limit value for PM10 $\left(50 \mu \mathrm{g} / \mathrm{m}^{3}\right)$ and PM2.5 (25 $\mu \mathrm{g} / \mathrm{m}^{3}$ ) set by Portuguese legislation (Decreto-Lei 118/2013). PM data (distributions and medians) of both fractions were significantly different $(p<0.05)$ across four clubs, across different places, and between both occupied and non- occupied periods. Note: for better visualization vertical axes y are shown in logarithmic scales; MWA identifies main workout areas; SGA are spaces for group activities. 
a)

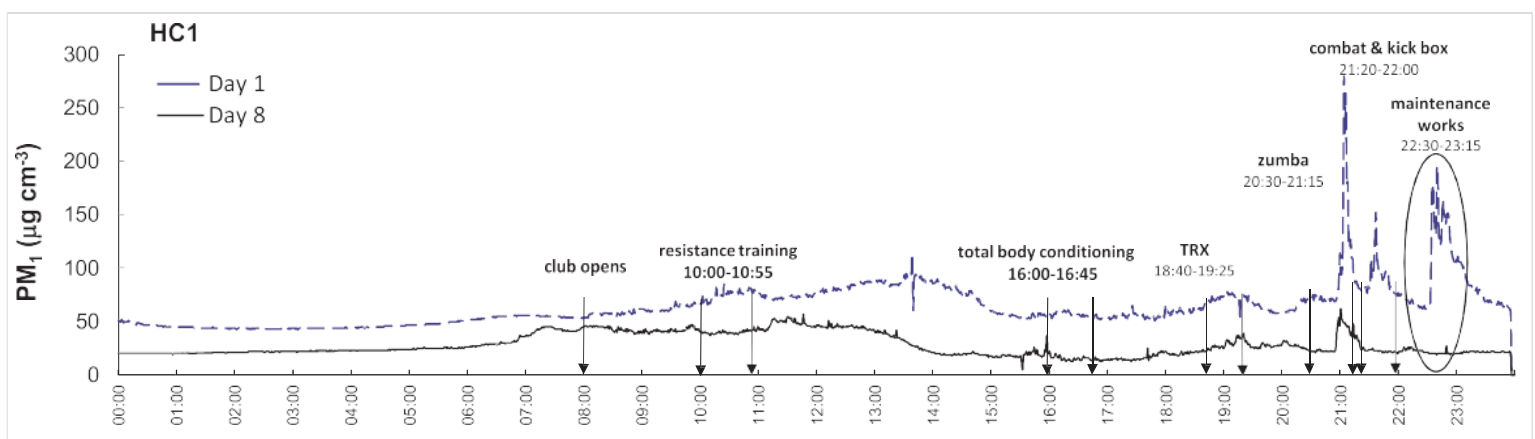

b)

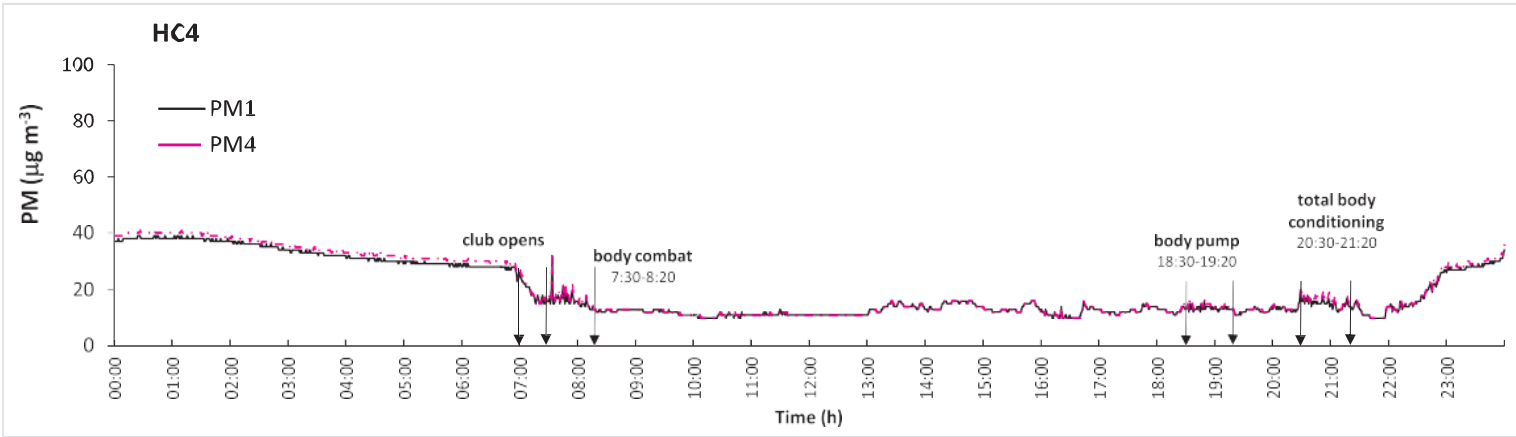

Fig. 5. Example of temporal variations of $P M$ in rooms/studios for group activities (SGA): (a) representation of PM1 profiles collected during the same weekdays at $\mathrm{HC1}$, with both profiles being relatively similar except for the concentration increase due to the maintenance works (blue / dashed line: 22:30-23:15); (b) PM1 and PM4 concentration profiles at HC4. Between midnight and $\sim 7$ a.m. profiles of both PM are very flat with almost no variation (noticeable drop of PM levels occurs at 6:50 when clubs opened and mechanical ventilation system were in use). (For interpretation of the references to colour in this figure legend, the reader is referred to the web version of this article). 

PM1/PM4 mass ratios were relatively high and ranged $0.78-1.00$ (median of 0.94 ) at $\mathrm{HC} 1,0.64-1.0(0.95)$ at HC2, 0.84-1.0 (0.93) at HC3, and 0.83-1.0 (0.96) at HC4. Whereas in $\mathrm{HC} 1$ and $\mathrm{HC} 2$ the large contribution of coarse fraction (PM4-1) was occasionally observed (36-46\%) due to outdoor infiltrations, overall PM1 composed $>90 \%$ of indoor particulates, which may be relevant considering the possible health impacts of small sized PM $[89,90]$. PM4 vs. PM1 daily profiles showed similar trends (Fig. $5 b$ ), being highly (and positively) correlated (Spearman correlation coefficients rs: 0.936 at $\mathrm{HC} 3-0.995$ at $\mathrm{HC} 4)$. In SGA, maxima of PM temporal variations were typically higher than in MWA, and occurred during high intensity cardio activities (Fig. 5a): HC1: 328-368 $\mu \mathrm{g} / \mathrm{m} 3$ during zumba; HC2: $638-829 \mu \mathrm{g} / \mathrm{m} 3$ during spinning; HC3: $53-58 \mu \mathrm{g} / \mathrm{m} 3$ during cardio muscular class; and HC4: $51-52 \mu \mathrm{g} / \mathrm{m} 3$ during body combat. Concerning HC4, it is necessary to remark that although PM levels were higher during off-hours $(p<0.05)$, the trends of concentration profiles during that time were stable with almost no variations (particularly during midnight-7 a.m.; Fig. 5b).

\subsection{Comfort parameters}

$\mathrm{T}$ and $\mathrm{RH}$ are among parameters that affect thermal comfort of the respective occupants. In general, $\mathrm{RH}$ levels recommended by different organizations range from 30 to $60 \%$. For $\mathrm{RH}$ of 30 and $60 \%$, ASHRAE recommends indoor $\mathrm{T}$ ranges $23.0-26.6^{\circ} \mathrm{C}$ and $23.0-$ $25.8^{\circ} \mathrm{C}$, respectively [91]. However, specifically for gyms, $\mathrm{RH} 55-75 \%$ and $\mathrm{T}$ range $18-$ $25^{\circ} \mathrm{C}$ (summer) are advised [92]. Typically, higher levels of $\mathrm{RH}$ were observed in all spaces when occupied (Fig. 6a). When exercising, breathing and perspiration generate substantial amount of water vapour, which impacts measured $\mathrm{RH}$ [13]. Furthermore, $\mathrm{RH}$ levels were moderately and positively correlated with $\mathrm{CO} 2$ ( $\mathrm{rs} 0.534$ at $\mathrm{HC}-0.625$ at HC1) pointing towards human activities contribution and exhalation during exercising. Whereas indoor conditions of $\mathrm{HC} 1$ and $\mathrm{HC} 4$ were within the recommended range (55$68 \%$; Fig. 6a); in MA of $\mathrm{C} 2$ and $\mathrm{C} 3, \mathrm{RH}$ were somewhat lower (44-48\%), which can cause some discomfort (drying nose, throat, mucous membranes and skin) [93,94].

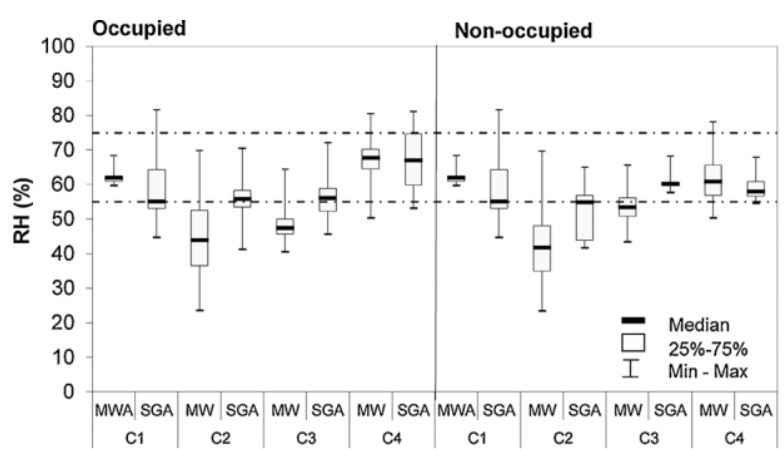

a)

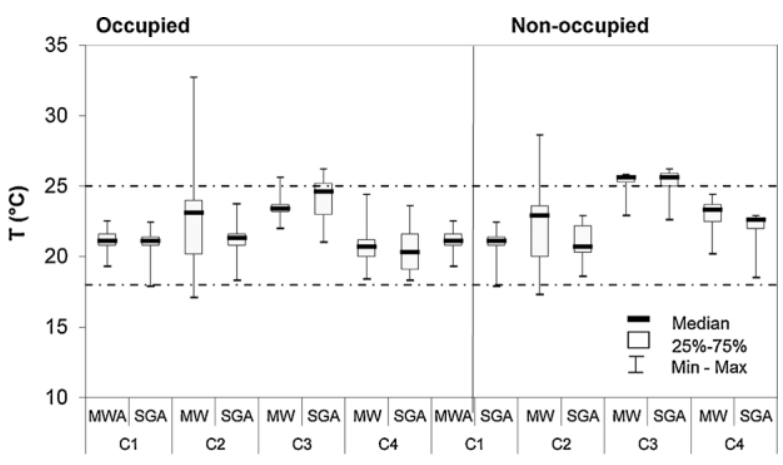

b)

Fig. 6. Comfort parameters ( median; $\square 25-75 \%$, and range) at health clubs 
( $\mathrm{HC} 1-\mathrm{HC} 4)$ during occupied and non-occupied periods: (a) relative humidity $(\mathrm{RH})$; (b) temperature $(T)$. Horizontal dashed lines represent indicated ranges for indoor spaces for sport practising (SEJD, 2008). Distributions and medians of parameter were significantly different $(p<0.05)$ across four clubs. Note: MWA identifies main workout areas; SGA are spaces for group activities.

In general, during occupied periods (Fig. 6b) $\mathrm{T}$ was within the recommended guidelines [95]. Higher exceedance (maxima value of $33^{\circ} \mathrm{C}$ ) was observed in MA of $\mathrm{C} 2$, which occurred during the laterafternoon period. As human body adds to room heat, accumulation of larger number of room occupants can increase air temperature [13]. However, considering the position and orientation of the rooms in HC2, T increase was most likely caused by sun shining; the room walls almost entirely consisted of glass panels (Table 1S) and entering heat power might warm up room air by few degrees [13]. As regular exercising in environmental conditions such as elevated $\mathrm{T}$ and increased $\mathrm{RH}$ can cause various health consequences [94,96,97], comfort parameters should be maintained within the recommended ranges (by proper use of air conditioning systems, room insulating, sun/heat reductions, and etc.).

\subsection{Inhalation dose assessment}

Total age- and gender-specific inhalation doses for different levels of physical activities are presented in Fig. 7, whereas doses estimated for each pollutant (gaseous, PM4 and PM1) are summarized in Table 7S. In agreement with the previous results, the highest magnitude of inhaled total doses (all ages and both genders) were in HC3 (1.6-3.5 times), which was the club with the poorest IAQ (Fig. 2, Fig. 4). Type of the conducted activities is relevant for the inhaled dose. More intense exercising (cardio classes) were associated with the highest doses (due to increased breathing); inhaled doses of cardio classes were approximately 1.7-1.9 (males) and 1.9-2.6 (females) times higher than for mind and body activities. Exercise duration is also important. As individual training lasts longer (approx. 20\% in this study), cardio vs. individual training doses comparison was much lower (1.0-1.17 for females, 1-1.12 for males). Furthermore, under this scenario, individual training included 20 min of warm-up session (high intensity breathing) and $40 \mathrm{~min}$ of body building (moderate inhalation), which also influenced the estimated doses. A comparison between both genders shows that women exhibited higher magnitude of inhaled doses (approx. 10-23\% more than males), most likely due to larger limitation of expiratory flow in females and, simultaneously, increased efforts to breath when intensely exercising [15]. However, gender specific parameters were retrieved from existent records [58] with higher variations of ventilatory patterns between different age categories of females than males [58]. Results summarized in Table 7S showed that CO2 accounted for majority ( 98\%) of the estimated inhaled doses. Nevertheless, $\mathrm{CO} 2$ is also a pollutant directly produced by human respiration [98]. Overall inhalation intakes of particulates $(\sim 0.3-1.3 \mu \mathrm{g} / \mathrm{kg})$ well corresponded to data $(0.2-2.1 \mu \mathrm{g} / \mathrm{kg})$ published by other authors $[48,99]$. Size of particles governs the deposition and removal rate within 
respiratory system. Type of respiration (i.e. nasal vs. oral) is also relevant as particle penetration into the lower respiratory tract is dependent on breathing route [100]. Secondly, elevated air flow velocity of breathing during exercising may cause transport of pollutants into the deepest part of the respiratory system, increasing the risk to human health [14]. Ozone inhaled doses were in similar ranges to PM $(0.7-3.1 \mu \mathrm{g} / \mathrm{kg})$ whereas inhalation dose of TVOCs ranged between $11-90 \mu \mathrm{g} / \mathrm{kg}$. For gaseous compounds, their solubility affects the inhaled uptake [101]. Apart from that, it is necessary to point out that pollutants studied within this work pose adverse health effects. Potentially synergic interactions between these pollutants seem to be indispensable factor when considering relationship between human exposure to air pollutants and adverse health effects. Despite the existing limitations for epidemiologic studies, synergism effects between ozone and other pollutants have been demonstrated in animal studies, and in limited capacity in human studies as well [102].

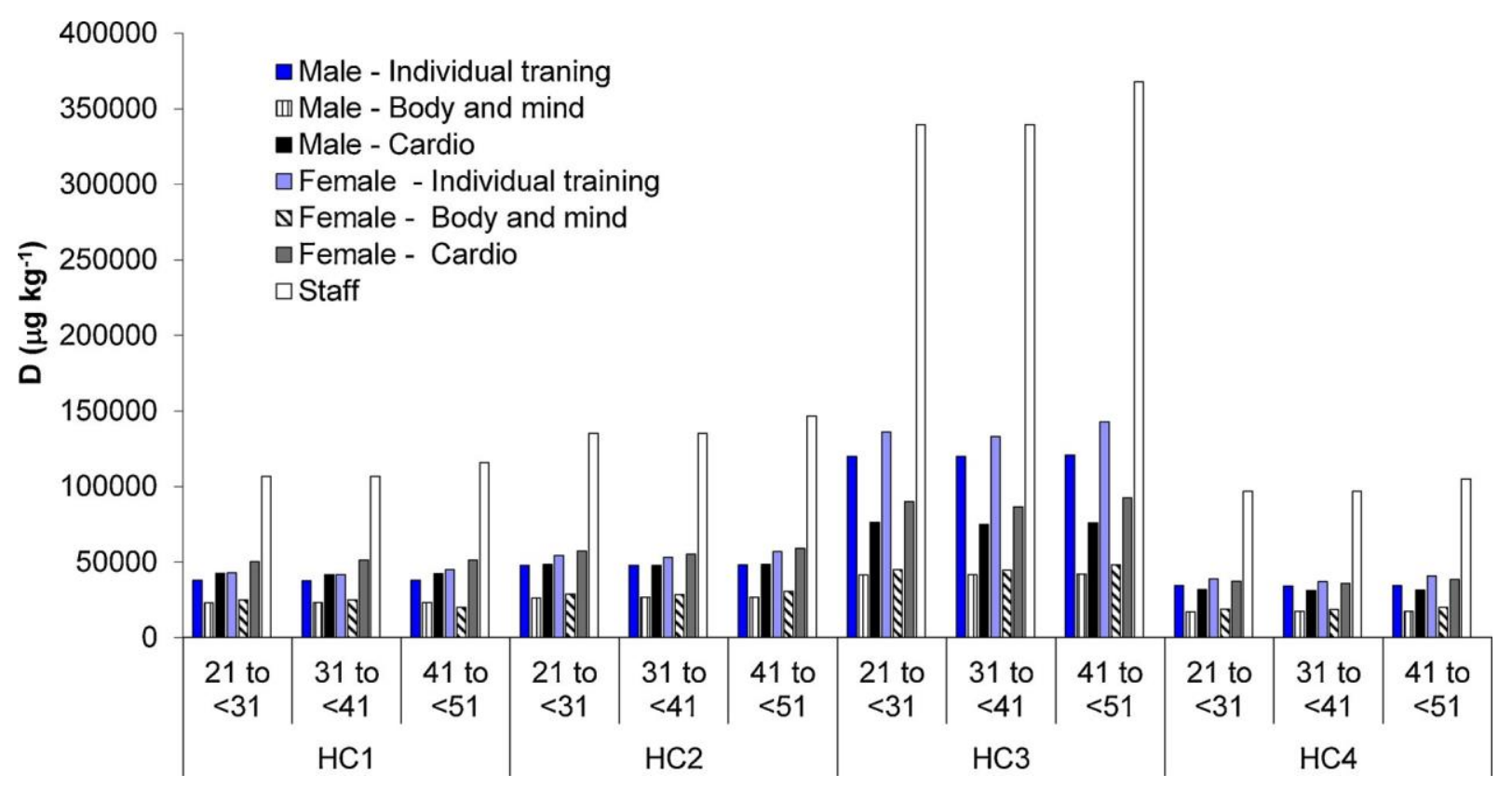

Fig. 7. Total gender- and age-specific inhaled doses $(\mu \mathrm{g} / \mathrm{kg})$ during different levels of physical activities. 
Inhalation doses of staff and instructors (male and female combined) who oversee the main workout area were also estimated. Obviously, large occupational duration (8-h) led to increased inhalation intakes (3-9 times higher than those who exercised). However, exposures to harmful pollutants in work places [110] represent just one microenvironment frequented on a daily basis. Therefore, other relevant microenvironments should be considered.

\section{Conclusions}

This study provides information on air quality in indoor environments for sport practise. Across four health clubs, concentrations of gaseous (TVOCs, O3, CO2) and particulate pollutants (PM4 and PM1) exhibited large temporal spatial variations. TVOCs highly exceeded limit of $600 \mu \mathrm{g} / \mathrm{m} 3$ designated by Portuguese legislation in all health clubs [60], even when these were unoccupied, thus indicating magnitude of potential risks for the respective occupants. The highest levels of all gaseous pollutants were observed in HC3, where CO2 levels exceeding the given standard of $1800 \mu \mathrm{g} / \mathrm{m} 3$ (even when the club was empty) indicate insufficient ventilation. In all analyzed clubs, $\mathrm{CO} 2$ was well correlated with relative humidity (rs $0.534-0.625$ ) and its daily profiles well agreed with occupancies, thus suggesting contribution of human activities (due exhalation during exercising). Overall, levels of gaseous and particulate pollutants were higher when clubs were occupied $(p<0.05)$ than for vacant periods, with larger medians observed in main workout areas rather than in spaces/studios for group exercise. Regarding PM, higher ( $\sim 2$ times) concentrations were observed at clubs with natural ventilations. PM1 accounted approximately for $93-96 \%$ of PM4; both PM were highly correlated (rs 0.936-0.995) pointing towards originating from the same emission sources.

Indoor chemistry of individual pollutants is complex. Additionally, during physical exercise, $I A Q$ is influenced by human occupancy and intensity of exercise. Inhalation dose of subjects in more demanding classes (cardio) resulted in 1.7-1.9 (males) and 1.9-2.6 (females) higher than in other types of exercising. Furthermore, female subjects inhaled during exercising about $10-23 \%$ higher doses than male ones, thus demonstrating the need to consider the differences between both genders in exposure studies. As knowledge regarding the associations between IAQ and health in indoor environments used for physical exercise is not well characterized yet, further assessments of potential exposure impacts and magnitude of inhaled pollutants are needed. 
National Funds (Fundação para a Ciência e Tecnologia) through projects UID/QUI/50006/2013 and UID/EQU/00511/2013-LEPABE, by FCT/MEC with national funds and co-funded by FEDER in the scope of the P2020 Partnership Agreement. Additional financial support was provided by FCT through fellowship SFRH/BPD/105100/2014.

References

[1] Global Burden of Disease Study (GBD), Mortality and causes of death collabora- tors. Global, regional, and national life expectancy, all-cause mortality, and cause- specific mortality for 249 causes of death, 1980-2015: a systematic analysis for the Global Burden of Disease Study 2015, Lancet 388 (2016) 2015, 1459-1454.

[2] P.J. Landrigan, R. Fuller, N.J.R. Acosta, O. Adeyi, R. Arnold, N.N. Basu, A.B. Baldé, R. Bertollini, S. Bose-O'Reilly, J.I. Boufford, P.N. Breysse, T. Chiles, C. Mahidol, A.M. Coll-Seck, M.L. Cropper, J. Fobil, V. Fuster, M. Greenstone, A. Haines, D. Hanrahan, D. Hunter, M. Khare, A. Krupnick, B. Lanphear, B. Lohani, K. Martin, K.V. Mathiasen, M.A. McTeer, C.J.L. Murray, J.D. Ndahimananjara, F. Perera, J. Potočnik, A.S. Preker, J. Ramesh, J. Rockström, C. Salinas, L.D. Samson, k. Sandilya, P.D. Sly, K.R. Smith, A. Steiner, R.B. Stewart, W.A. Suk, O.C.P. van Schayck, G.N. Yadama, K. Yumkella, M. Zhong, The Lancet Commission on pollution and health, Lancet 391 (10119) (2018) 462-512, https://doi.org/10.1016/ S0140-6736(17)32345-0.

[3] S.T. Holgate, Every breath we take. Clinical medicine, J. R. Coll. Physicians Lond.

17 (1) (2017) 8-12.

[4] M. Mazidi, J.R. Speakman, Ambient particulate air pollution (PM2.5) is associated with the ratio of type 2 diabetes to obesity, Sci. Rep. 7 (1) (2017) 9144.

[5] P.C. Hallal, L.B. Andersen, F.C. Bull, R. Guthold, W. Haskell, U. Ekelund, Lancet Physical Activity Series Working Group, Global physical activity levels: surveil- lance progress, pitfalls, and prospects, Lancet 380 (9838) (2012) 247-257.

[6] I.M. Lee, E.J. Shiroma, F. Lobelo, P. Puska, S.N. Blair, P.T. Katzmarzyk, Lancet Physical Activity Series Working Group, Effect of physical inactivity on major non- communicable diseases worldwide: an analysis of burden of disease and life ex- pectancy, Lancet 380 (9838) (2012) 219-229.

[7] World Health Organization (WHO), European Food and Nutrition Action Plan 
2015-2020, WHO Regional Office for Europe, Copenhagen, Denmark, 2015, p. 1. [8] K.H. Kim, E. Kabir, S. Kabir, A review on the human health impact of airborne particulate matter, Environ. Int. 74 (2015) 136-143.

[9] G. Buonanno, F.C. Fuoco, S. Marini, L. Stabile, Particle resuspension in school gyms during physical activities, Aerosol Air Qual. Res. 12 (5) (2012) 803813.

[10] N.B. Goodman, A. Steinemann, A.J. Wheeler, P.J. Paevere, M. Cheng, S.K. Brown, Volatile organic compounds within indoor environments in Australia, Build.

Environ. 122 (2017) 116-125.

[11] N. Hodas, M. Loh, H.-M. Shin, D. Li, D. Bennett, T.E. McKone, O. Jolliet, C.J. Weschler, M. Jantunen, P. Lioy, P. Fantke, Indoor inhalation intake fractions of fine particulate matter: review of influencing factors, Indoor Air 26 (6) (2016) 836-856.

[12] M. Braniš, J. Šafránek, Characterization of coarse particulate matter in school gyms, Environ. Res. 111 (4) (2011) 485-491.

[13] M. Žitnik, K. Bučar, B. Hiti, Ž. Barba, Z. Rupnik, A. Založnik, E. Žitnik, L. Rodrìguez, I. Mihevc, J. Žibert, Exercise-induced effects on a gym atmosphere, Indoor Air 26 (3) (2016) 468-477.

[14] A. Andrade, F.H. Dominski, D.R. Coimbra, Scientific production on indoor air quality of environments used for physical exercise and sports practice: bibliometric analysis, J. Environ. Manage. 196 (2017) 188-200.

[15] C.A. Ramos, J.F. Reis, T. Almeida, F. Alves, H.T. Wolterbeek, S.M. Almeida, Estimating the inhaled dose of pollutants during indoor physical activity, Sci. Total Environ. 527-528 (2015) 111-118.

[16] I. Annesi-Maesano, N. Baiz, S. Banerjee, P. Rudnai, S. Rive, on behalf of the SINPHONIE Group, Indoor air quality and sources in schools and related health effects, J. Toxicol. Environ. Health Part B Crit. Rev. 16 (2013) 491-550.

[17] G. Bekö, C.J. Weschler, A. Wierzbicka, D.G. Karottki, J. Toftum, S. Loft, G. Clausen, Ultrafine particles: exposure and source apportionment in 56 Danish homes, Environ. Sci. Technol. 47 (18) (2013) 10240-10248.

[18] D. Campagnolo, D.E. Saraga, A. Cattaneo, A. Spinazzè, C. Mandin, R. Mabilia, E. Perreca, I. Sakellaris, N. Canha, V.G. Mihucz, T. Szigeti, G. Ventura, J. Madureira, E. de Oliveira Fernandes, Y. de Kluizenaar, E. Cornelissen, O. Hänninen, P. Carrer, P. Wolkoff, D.M. Cavallo, J.G. Bartzis, VOCs and aldehydes source identification in European office buildings - the OFFICAIR study, Build. Environ. 115 (2017) 18-24.

[19] J. Cavaleiro Rufo, J. Madureira, I. Paciência, K. Slezakova, M.C. Pereira, L. 
Aguiar,

J.P. Teixeira, A. Moreira, E. Oliveira Fernandes, Children exposure to indoor ultrafine particles in urban and rural school environments, Environ. Sci. Pollut. Res. 23 (14) (2016) 13877-13885.

[20] L. Morawska, G.A. Ayoko, G.N. Bae, G. Buonanno, C.Y.H. Chao, S. Clifford, S.C. $\mathrm{Fu}$,

O. Hänninen, C. He, C. Isaxon, M. Mazaheri, T. Salthammer, M.S. Waring, A. Wierzbicka, Airborne particles in indoor environment of homes, schools, offices and aged care facilities: the main routes of exposure, Environ. Int. 108 (2017) 75-83.

[21] H. Maula, V. Hongisto, V. Naatula, A. Haapakangas, H. Koskela, The effect of low ventilation rate with elevated bioeffluent concentration on work performance, perceived indoor air quality and health symptoms, Indoor Air 27 (6) (2017) 1141-1153.

[22] M. Oliveira, K. Slezakova, C. Delerue-Matos, M.C. Pereira, S. Morais, Indoor air quality in preschools (3- to 5-year-old children) in the Northeast of Portugal during spring-summer season: pollutants and comfort parameters, J. Toxicol. Environ. Health Part A Curr. Issues 80 (13-15) (2017) 740-755.

[23] M. Oliveira, K. Slezakova, J. Madureira, E. Oliveira Fernandes, C. Delerue Matos,

S. Morais, M.C. Pereira, Polycyclic aromatic hydrocarbons in primary school environments: levels and potential risks, Sci. Total Environ. 575 (2017) 1156-1167. [24] M. Oliveira, K. Slezakova, C. Delerue-Matos, M.C. Pereira, S. Morais, Assessment of exposure to polycyclic aromatic hydrocarbons in preschool children: levels and impact of preschool indoor air on excretion of main urinary monohydroxyl me- tabolites, J. Hazard. Mater. 322 (2017) 357-369.

[25] M. Oliveira, K. Slezakova, C. Delerue-Matos, M.C. Pereira, S. Morais, Assessment of air quality in preschool environments (3-5 years old children) with emphasis on elemental composition of PM10 and PM2.5, Environ. Pollut. 214 (2016) 430-439.

[26] M.L. Pereira, L.D. Knibbs, C. He, P. Grzybowski, G.R. Johnson, J.A. Huffman, S.C. Bell, C.E. Wainwright, D.L. Matte, F.H. Dominski, A. Andrade, L. Morawska, Sources and dynamics of fluorescent particles, Indoor Air 27 (2017) 988-1000. [27] K. Slezakova, M.C. Alvim-Ferraz, M.C. Pereira, Elemental characterization of in-

door breathable particles at a Portuguese urban hospital, J. Toxicol. Environ. Health Part A Curr. Issues 75 (13-15) (2012) 909-919.

[28] K. Slezakova, S. Morais, M.C. Pereira, Trace metals in size-fractionated 
particulate matter in a Portuguese hospital: exposure risks assessment and comparisons with other countries, Environ. Sci. Pollut. Res. 21 (5) (2014) 36043620.

[29] F. Azarmi, P. Kumar, M. Mulheron, The exposure to coarse, fine and ultrafine particle emissions from concrete mixing, drilling and cutting activities, J. Hazard. Mater. 279 (2014) 268-279.

[30] J. Martin, D. Bello, K. Bunker, M. Shaferd, D. Christiani, S. Woskie, P. Demokritou, Occupational exposure to nanoparticles at commercial photocopy centers, J. Hazard. Mater. 298 (2015) 351-360.

[31] B.P. Singh, A. Kumar, D. Singh, M. Punia, K. Kumar, V.K. Jain, An assessment of ozone levels, UV radiation and their occupational health hazard estimation during photocopying operation, J. Hazard. Mater. 275 (2014) 55-62. [32] C.A. Alves, A.I. Calvo, A. Castro, R. Fraile, M. Evtyugina, E.F. Bate-Epey, Indoor air quality in two university sports facilities, Aerosol Air Qual. Res. 13 (6) (2013) 1723-1730.

[33] C. Alves, A.I. Calvo, L. Marques, A. Castro, T. Nunes, E. Coz, R. Fraile, Particulate matter in the indoor and outdoor air of a gymnasium and a fronton, Environ. Sci.

Pollut. Res. 21 (21) (2014) 12390-12402.

[34] M. Braniš, J. Šafránek, A. Hytychová, Exposure of children to airborne particulate matter of different size fractions during indoor physical education at school, Build. Environ. 44 (6) (2009) 1246-1252.

[35] M. Braniš, J. Šafránek, A. Hytychová, Indoor and outdoor sources of sizeresolved mass concentration of particulate matter in a school gym-implications for ex-posure of exercising children, Environ. Sci. Pollut. Res. 18 (4) (2011) 598-609. [36] A. Castro, A.I. Calvo, C. Alves, E. Alonso-Blanco, E. Coz, L. Marques, T. Nunes, J.M. Fernández-Guisuraga, R. Fraile, Indoor aerosol size distributions in a gymnasium, Sci.Total Environ. 524-525 (2015) 178-186.

[37] J. Fonseca, K. Slezakova, S. Morais, M.C. Pereira, Assessment of ultrafine particles in Portuguese preschools: levels and exposure doses, Indoor Air 24 (6) (2014) 618-628.

[38] P. Kic, Dust pollution in the sport facilities, Agron. Res. 14 (1) (2016) 75-81.

[39] Z. Szoboszlai, E. Furu, A. Angyal, Z. Szikszai, Z. Kertész, Hungary X-Ray Spectr. 40 (3) (2011) 176-180.

[40] T.J. Ward, C.P. Palmer, K. Hooper, M. Bergauff, C.W. Noonan, The impact of a community-wide woodstove changeout intervention on air quality within two schools, Atmos. Pollut. Res. 4 (2) (2013) 238-244.

[41] D.S. Bisht, S. Tiwari, A.K. Srivastava, A.K. Srivastava, Assessment of air quality during 19th Common Wealth Games at Delhi India, Nat. Hazards 66 (2) 
(2013) 141-154.

[42] T.S. Filipe, M. Vasconcelos Pinto, J. Almeida, C. Alcobia Gomes, J.P.

Figueiredo, A. Ferreira, Indoor air quality in sports halls, Occupational Safety and Hygiene - Proceedings of the International Symposium on Occupational Safety and Hygiene, SHO 2013, 2013, pp. 175-179.

[43] S.-J.N. Goung, J. Yang, Y.S. Kim, C.M. Lee, A pilot study of indoor air quality in screen golf courses, Environ. Sci. Pollut. Res. 9 (2015) 7176-7182.

[44] O.I. Stathopoulou, V.D. Assimakopoulos, H.A. Flocas, C.G. Helmis, An experimental study of air quality inside large athletic halls, C.G. Build. Environ. 43 (5) (2008) 834-848.

[45] S. Weinbruch, T. Dirsch, K. Kandler, M. Ebert, G. Heimburger, F. Hohenwarter, Reducing dust exposure in indoor climbing gyms, J. Environ. Monit. 14 (8) (2012) 2114-2120.

[46] S.-M. Hug, R. Hansmann, C. Monn, P. Krütli, K. Seeland, Restorative effects of physical activity in forests and indoor settings, Int. J. Fitness 4 (2) (2008) 2538.

[47] D.E. Saraga, L. Volanis, T. Maggos, C. Vasilakos, K. Bairachtari, C.G. Helmis, Workplace personal exposure to respirable PM fraction: a study in sixteen indoor environments, Atmos. Pollut. Res. 5 (3) (2014) 431-437.

[48] C.A. Ramos, H.T. Wolterbeek, S.M. Almeida, Exposure to indoor air pollutants during physical activity in fitness centers, Build. Environ. 82 (2014) 349-360. [49] K. Slezakova, C. Peixoto, M. Oliveira, C. Delereu-Matos, M.C. Pereira, S. Morais, Indoor particulate pollution in fitness centres with emphasis on ultrafine particles, Environ. Pollut. 233 (2018) 180-193.

[50] World Health Organization (WHO), Global Recommendations on Physical Activity for Health, World Health Organization, Copenhagen, Denmark, 2010. [51] K. Slezakova, D. Castro, A. Begonha, C. Delerue-Matos, M.C. Alvim-Ferraz, S. Morais, M.C. Pereira, Air pollution from traffic emissions in oporto, Portugal: health and environmental implications, Microchem. J. 99 (1) (2013) 51-59. [52] K. Slezakova, J.C. Pires, D. Castro, M.C. Alvim-Ferraz, C. Delerue-Matos, S. Morais, M.C. Pereira, PAH air pollution at a Portuguese urban area: carcinogenic risks and sources identification, Environ. Sci. Pollut. Res. 20 (6) (2013) 39323945.

[53] S. Holmberg, Y. Li, Modelling of the indoor environment e particle dispersion and deposition, Indoor Air 8 (1998) 113-122.

[54] H. Jin, C. He, L. Lu, J. Fan, Numerical investigation of the wall effect on airborne particle dispersion in a test chamber, Aerosol Air Qual. Res. 13 (2013) 786-794. 
[55] I. Rivas, M. Mazaheri, M. Viana, T. Moreno, S. Clifford, C. He, O.F. Bischof, V. Martins, C. Reche, A. Alastuey, M. Alvarez-Pedrerol, J. Sunyer, L. Morawska, $X$. Querol, Identification of technical problems affecting performance of DustTrak DRX aerosol monitors, Sci. Total Environ. 584-585 (2017) 849-855.

[56] K. Slezakova, C. Texeira, S. Morais, M.C. Pereira, Children's indoor exposures to (ultra)fine particles in an urban area: comparison between school and home en- vironments, J. Toxicol. Environ. Health Part A Curr. Issues 78 (13) (2015) 886-896.

[57] K. Slezakova, J. Fonseca, S. Morais, M.C. Pereira, Ultrafine particles in ambient air of an urban area: dose implications for elderly, J. Toxicol. Environ. Health Part A: Curr. Issues 77 (14-16) (2014) 827-836.

[58] U.S. Environmental Protection Agency (USEPA), Exposure Factors Handbook, 2011 edition (final), Environmental Protection Agency, Washington, DC, U.S, 2011.

[59] World Health Organization (WHO), WHO Guidelines for Indoor Air Quality: Selected Pollutants, WHO Regional Office for Europe, Copenhagen, Denmark, 2010.

[60] Decreto-Lei 118/2013. O sistema de certificação energética dos edifícios, o reg- ulamento de desempenho energético dos edifícios de habitação e o regulamento de desempenho Energético dos edifícios de comércio e serviços (in Portuguese). Diário da República,1. a série - N. 235, 6644(1)-6644 (10).

[61] R.L. Corsi, J. Siegel, A. Karamalegos, H. Simon, G.C. Morrison, Personal reactive clouds: introducing the concept of near-head chemistry, Atmos. Environ. 41 (2007) 3161-3165.

[62] X. Tang, P.K. Misztal, W.W. Nazaroff, A.H. Goldstein, Volatile organic compound emissions from humans indoor, Environ. Sci. Technol. 50 (23) (2016) 12686-12694.

[63] B. de Lacy Costello, A. Amann, H. Al-Kateb, C. Flynn, W. Filipiak, T. Khalid, D. Osborne, N.M. Ratcliffe, A review of the volatiles from the healthy human body, J. Breath Res. 8 (1) (2014) 014001. 
[64] T. Dutta, K.-H. Kim, M. Uchimiya, P. Kumar, S. Das, S.S. Bhattacharya, J. Szulejko, The micro-environmental impact of volatile organic compound emissions from large-scale assemblies of people in a confined space, Environ. Res. 51 (2016) 304-312.

[65] X. Sun, J. He, X. Yang, Human breath as a source of VOCs in the built environment, part II: concentration levels, emission rates and factor analysis, Build. Environ. 123 (2017) 437-445.

[66] K. Gao, J. Xie, X. Yang, Estimation of the contribution of human skin and ozone reaction to volatile organic compounds (VOC) concentration in aircraft cabins, Build. Environ. 94 (2015) 12-20.

[67] A. Wisthaler, C.J. Weschler, Reactions of ozone with human skin lipids: sources of carbonyls, dicarbonyls, and hydroxycarbonyls in indoor air, Proc. Natl. Acad. Sci. U. S. A. 107 (2010) 6568-6575.

[68] M. Odabasi, Halogenated volatile organic compounds from the use of chlorine- bleach- containing household products, Environ. Sci. Technol. 42 (5) (2008) 1445-1451.

[69] Persily, Evaluating building IAQ and ventilation with indoor carbon dioxide, ASHRAE Trans. 10 (2) (1997).

[70] U. Satish, M.J. Mendell, K. Shekhar, T. Hotchi, D. Sullivan, S. Streufert, J.W. Fisk, Is $\mathrm{CO} 2$ an indoor pollutant? Direct effects of low-to-moderate $\mathrm{CO} 2$ concentrations on human decision-making performance, Environ. Health Perspect. 120 (12) (2012) 1671-1677.

[71] T. Tuomi, B. Engström, R. Niemelä, J. Svinhufvud, K. Reijula, Emission of ozone and organic volatiles from a selection of laser printers and photocopiers, Appl. Occup. Environ. Hyg. 15 (8) (2000) 629-634.

[72] M.S. Waring, J.A. Siegel, R.L. Corsi, Ultrafine particle removal and generation by portable air cleaners, Atmos. Environ. 42 (2008) 5003-5014. [73] American Society of Heating, Refrigerating, and Air-Conditioning Engineers (ASHRAE), Environmental Health Committee Emergy Issue Report: Ozone and Indoor Chemistry, (2011).

[74] A.C. Rohr, The health significance of gas- and particle-phase terpene oxidation products: a review, Environ. Int. 60 (2013) 145-162.

[75] C.J. Weschler, Ozone's impact on public health: contributions from indoor ex-posures to ozone and products of ozone-initiated chemistry, Environ. Health Perspect. 114 (2006) 1489-1496.

[76] C.J. Weschler, H.C. Shields, Production of the hydroxyl radical in indoor air, Environ. Sci. Technol. 30 (1996) 3250-3258.

[77] C.J. Weschler, A. Wisthaler, S. Cowlin, G. Tamás, P. Strøm-Tejsen, A.T. 
Hodgson,

H. Destaillats, J. Herrington, J. Zhang, W.W. Nazaroff, Ozone-initiated chemistry in an occupied simulated aircraft cabin, Environ. Sci. Technol. 41 (2007) 61776184.

[78] P. Wolkoff, C.K. Wilkins, P.A. Clausen, G.D. Nielsen, Organic compounds in office environments - sensory irritation, odor, measurements and the role of reactive chemistry, Indoor Air (2006) 7-19.

[79] D. Rim, A. Novoselec, G.C. Morrison, The influence of chemical interactions at thehuman surface on the breathing-zone levels of reactants and products, Indoor Air 19 (2009) 324-334.

[80] C. Weisel, C.J. Weschler, K. Mohan, J. Vallarino, J.D. Spengler, Ozone and ozone byproducts in the cabins of commercial aircraft, Environ. Sci. Technol. 47 (9) (2013) 4711-4717.

[81] J.F. Montgomery, S. Storey, K. Bartlett, Comparison of the indoor air quality in an office operating with natural or mechanical ventilation using short-term intensive pollutant monitoring, Indoor Built Environ. 24 (6) (2015) 777-787.

[82] G. Loupa, I. Kioutsioukis, S. Rapsomanikis, Indoor-outdoor atmospheric particu- late matter relationships in naturally ventilated offices, Indoor Built Environ. 16 (2007) 63-69.

[83] G.M. Revel, M. Arnesano, Perception of the thermal environment in sports facil- ities through subjective approach, Build. Environ. 77 (2014) 12-19.

[84] S.M. Almeida, C.A. Ramos, M. Almeida-Silva, Exposure and inhaled dose of sus- ceptible population to chemical elements in atmospheric particles, J. Radioanal. Nucl. Chem. 309 (1) (2016) 309-315.

[85] L. Morawska, A. Afshari, G.N. Bae, G. Buonanno, C.Y.H. Chao, O. H€anninen, W. Hofmann, C. Isaxon, E.R. Jayaratne, P. Pasanen, T. Salthammer, M. Waring,

A. Wierzbicka, Indoor aerosols: from personal exposure to risk assessment, Indoor Air 23 (2013) 462-487.

[86] J. Madureira, I. Paciência, J. Rufo, M. Severo, E. Ramos, H. Barros, E. de Oliveira Fernandes, Source apportionment of CO2, PM10 and VOCs levels and health risk assessment in naturally ventilated primary schools in Porto, Portugal, Build.

Environ. 96 (2016) 198-205.

[87] J. Molinié, V. Clotaire, R. Plocoste, H. Petit, Night outdoor air as a major source of indoor air particle concentrations in an office, Proceedings of the 91st American Meteorological Society, Washington, USA, 2011.

[88] I.K. Ortega, T. Suni, M. Boy, T. Grönholm, H.E. Manninen, T. Nieminen, M. Ehn, 
H. Junninen, H. Hakola, H. Hellén, T. Valmari, H. Arvela, S. Zegelin, D. Hughes, M. Kitchen, H. Cleugh, D.R. Worsnop, M. Kulmala, New insights into nocturnal nucleation, Atmos. Chem. Phys. 12 (9) (2012) 4297-4312.

[89] S. Feng, D. Gao, F. Liao, F. Zhou, X. Wang, The health effects of ambient PM2.5 and potential mechanisms, Ecotoxicol. Environ. Saf. 128 (2016) 67-74. [90] K. Widziewicz, K. Loska, Metal induced inhalation exposure in urban population: a probabilistic approach, Atmos. Environ. 128 (2016) 198-207. [91] American Society of Heating, Refrigerating, and Air-Conditioning Engineers (ASHRAE), ASHRAE Technical FAQ ID 92, Accessed online December 2017. Available at https://www.ashrae.org/File\%20Library/docLib/Technology/.../TC02.01-FAQ-92.pdf (2017).

[92] SEJD, Ginásios: Diploma relativo à construção, instalação e funcionamento, Available at Secretariat of State for Youth and Sport, Lisbon Portugal. Presidency

of the Council of Ministers, Secretariat of state for Youth and Sport, 2008, http:// www.cd.ubi.pt/artigos/Gin\%C3\%A1sios.pdf.

[93] D. Bélanger, P. Gosselin, P. Valois, B. Abdous, Perceived adverse health effects of heat and their determinants in deprived neighbourhoods: a crosssectional survey of nine cities in Canada, Int. J. Environ. Res. Public Health 11 (11) (2014) 11028-11053.

[94] J.E. Sylvester, L.N. Belval, D.J. Casa, F.G. O'Connor, Exertional heat stroke and American football: awat the team physician needs to know, Am. J. Orthop. 45 (6) (2016) 340-348.

[95] Y. Geng, W. Ji, B. Lin, Y. Zhu, The impact of thermal environment on occupant IEQ perception and productivity, Build. Environ. 121 (2017) 158-167.

[96] S. Racinais, M. Mohr, M. Buchheit, S.C. Voss, N. Gaoua, J. Grantham, L. Nybo, Individual responses to short-term heat acclimatisation as predictors of football performance in a hot, dry environment, Br. J. Sports Med. 46 (11) (2012) 810-815.

[97] B. Roelands, K. De Pauw, R. Meeusen, Neurophysiological effects of exercise in the heat, 2015, Scand. J. Med. Sci. Sports 25 (S1) (2015) 65-78 1.

[98] A. Persily, L. de Jonge, Carbon dioxide generation rates for building occupants, Indoor Air 27 (5) (2017) 868-879.

[99] L.I. Panis, B. Geus, G. Vandenbulcke, H. Willems, B. Degraeuwe, N. Bleux, V. Mishra, I. Thomas, R. Meeusen, Exposure to particulate matter in traffic: a comparison of cyclists and car passengers, Atmos. Environ. 44 (2010) 22632270 .

[100] J.S. Brown, T. Gordon, O. Price, B. Asgharian, Thoracic and respirable particle definitions for human health risk assessment, Part. Fibre Toxicol. 10 (1) 
(2013) 12.

[101] A.Y. Bigazzi, M.A. Figliozzi, Review of urban bicyclists' intake and uptake of traffic related air pollution, Transp. Rev. 34 (2) (2014) 221-245.

[102] J.L. Mauderly, J.M. Samet, Is there evidence for synergy among air pollutants in causing health effects? Environ. Health Perspect. 117 (1) (2009) 16.

[103] N. Canha, J. Lage, S. Candeias, C. Alves, S.M. Almeida, Indoor air quality during sleep under different ventilation patterns, Atmos. Pollut. Res. 8 (2017) 1132-1142.

[104] P.N. Pegas, C.A. Alves, M.G. Evtyugina, T. Nunes, M. Cerqueira, M. Franchi, C.A. Pio, S.M. Almeida, S.C. Verde, M.C. Freitas, Seasonal evaluation of outdoor/ indoor air quality in primary schools in Lisbon, J. Environ. Monit. 13 (3) (2011) 657-667.

[105] Directive 2008/50/EC of the European Parliament and of the Council on ambient air quality and cleaner air for Europe, Off. J. Eur. Union L152 (2008) 144.

[106] C.J. Weschler, Ozone in indoor environments: concentration and chemistry, Indoor Air 10 (2000) 269-288.

[107] S. Walker, Max H. Sherman, Effect of ventilation strategies on residential ozone levels, Build. Environ. 59 (2013) 456-465.

[108] World Health Organization (WHO), Air Quality Guidelines: Global Update 2005, World Health Organization, Regional Office for Europe, Copenhagen, 2006.

[109] European Environment Agency (EEA), Air Quality in Europe - 2016 Report, European Environment Agency, Publications Office of the European Union, Luxembourg, 2016.

[110] M. Žitnik, A. Kastelic, Z. Rupnik, P. Pelicon, P. Vaupetič, K. Bučar, S. Novak, S. Samardžija, S. Matsuyama, G. Catella, K. Ishii, Time-resolved measurements of aerosol elemental concentrations in indoor working environments, Atmos. Environ. 44 (2010) 4954-4963. 